\title{
Effect of Gamma Irradiation on the Structural and Optical Properties of $\mathrm{ZnO}$ Thin Films
}

\author{
Najiba A. Al- Hamdani Ramla D. Al-Alawy Saba J. Hassan \\ Physics Department, Education College, Al-Mustansiriyah University, Baghdad-Iraq.
}

\begin{abstract}
Zinc oxide (ZnO) thin films were prepared by DC- magnetron sputtering technique on glass at 500 ${ }^{0} \mathrm{C}$ substrates temperature. The effect of $\gamma$-irradiation on the structure and optical properties of the films was investigated. The crystal structure and orientation of the films were studded by XRD pattern. The deposited film is polycrystalline and the dependence of preferred orientation, peak intensities and grain size on the gamma ( $\gamma)$ irradiation are investigated. The absorption and transmission spectra recorded in the UV/VIS/NIR region for the as deposited and irradiated films The absorption coefficient, optical energy gap, Urbach energy, optical constants (refractive index, extinction coefficient, dielectric constant) and dispersion parameters, such as single-oscillator energy, dispersive energy were determined of irradiated and un-irradiated samples and analyzed.
\end{abstract}

Keywords: Zinc oxide (ZnO), thin film, $\gamma$-irradiation, optical properties, Structural properties, DC- magnetron sputtering.

\section{Introduction}

The large scale uses of conductive transparent films for optoelectronic device such as solar cells and displays have led to the development of a variety of film preparation techniques. $\mathrm{ZnO}$ is a technologically one of important materials. It have been investigated over the last four decades because of their interesting optical, piezoelectric and electrical properties. The stability of these films, however, at high temperature and high radiation environment is still a matter of research [1-3]. Interaction of radiant energy with matter, especially $\gamma$ radiation, is an extremely important from the view point of theory and practice. When solid material exposure to ionizing radiations produces changes in the microstructural properties of the material, which in turn affects the optical, electrical and other physical properties of the material [4-6]. Numerous efforts have recently been made to investigate the influence of gamma radiation on thin films and thin film structures of different metal oxides and polymers, in order to find out the suitability of using thin films and thin film structures of different metal oxides and polymers as gamma radiation dosimeters [7-10]. Physical properties of $\mathrm{ZnO}$ are strongly influenced by the growth parameters and the post deposition treatments [11]. The present investigation was carried out in an attempt to investigated the effect of $\gamma$-rays radiation on the structure and optical properties of $\mathrm{ZnO}$ thin films prepared by DC- magnetron sputtering technique.

\section{Experimental}

The $\mathrm{ZnO}$ thin films were prepared by using DC-magnetron sputtering source Edwards 306 pumping system. The sputtering conditions are: Target - anode distance $(30 \mathrm{~mm})$, substrate type (glass), at $500^{\circ} \mathrm{C}$ substrates temperature, magnetic field $570 \mathrm{G}$, DC power $50 \mathrm{~W}$, gas pressure $7 \times 10^{-2}$ Torr and at atmosphere of argon $100 \%$. $\mathrm{ZnO}$ thin films were sputtered from target's on the glass. The target materials are in the form of plates with $60 \mathrm{~mm}$ diameter and $2 \mathrm{~mm}$ thickness made from $\mathrm{ZnO}$ powder ( $99.98 \%$ purity).

The film thickness was measured by scanning Electron microscope (SEM). The film thickness was measured to be about $(800 \pm 10 \mathrm{~nm})$ using the cross-section scanning electron microscopy (SEM) image as shown in Fig (1).

X-ray diffraction XRD measurements were carried out to characterize the formation of the sample structures. The optical properties were measured UV/VIS/ NIR spectrophotometer with double beam. The X-ray diffraction and optical absorption measurements were carried at before and after irradiation of the sample by $\gamma$ irradiation. $\mathrm{ZnO}$ thin films were exposed to $\gamma$ - ray results from ${ }^{137} \mathrm{Cs}$ source with active radiation $(0.36 \mu \mathrm{ci})$ and gamma emission energy is $0.662 \mathrm{MeV}$ for 21 day at room temperature.

\section{i. X-ray diffraction studies}

\section{Results and discussion}

Fig. (2) shows the XRD of $\mathrm{ZnO}$ thin film before and after the irradiation. X-ray diffraction analysis indicates that for un-irradiated and irradiated film are polycrystalline with hexagonal structure and show a good C-axis orientation perpendicular to the substrate surface. The sharp and strong peak (002) observed at $2 \theta=34.24^{\circ}$ 
$(\mathrm{d}=2.616 \AA)$ and at $2 \theta=34.55^{\circ}(\mathrm{d}=2.594 \AA)$ for un-irradiated and irradiated film respectively as shown in table(1), which are found to be in agreement with the standard value of ASTM [12]. By using the Miller indices of these planes, the lattice parameters a and $\mathrm{c}$ of the unit cell is evaluated according to the relation [13]:

$\frac{1}{d^{2}}=\frac{4}{3}\left[\frac{h^{2}+h k+k^{2}}{a^{2}}\right]+\frac{l^{2}}{c^{2}}$

Where $\mathrm{d}$ is the interplanar spacing and (hkl) are the Miller indices. It was seen that the calculated values are in good agreement with the standard values for $\mathrm{ZnO}$ wurtzite structure [12].

Table (1): lattice constant ASTM, irradiated and Un-irradiated of ZnO films

\begin{tabular}{|c|c|c|c|c|c|c|c|c|c|c|c|}
\hline \multicolumn{5}{|c|}{ ASTM } & \multicolumn{5}{|c|}{ Un irradiated } & \multicolumn{4}{|c|}{ Irradiated } \\
\hline $2 \Theta$ & $\mathrm{d}(\AA)$ & $\mathrm{a}(\AA)$ & $\mathrm{c}(\AA)$ & $2 \Theta$ & $\mathrm{d}(\AA)$ & $\mathrm{a}(\AA)$ & $\mathrm{c}(\AA)$ & $2 \Theta$ & $\mathrm{d}(\AA)$ & $\mathrm{a}(\AA)$ & $\mathrm{c}(\AA)$ \\
\hline $34.44^{\circ}$ & 2.60 & 3.25 & 5.205 & $34.24^{\circ}$ & 2.62 & 3.25 & 5.23 & $34.55^{\circ}$ & 2.59 & 3.26 & 5.19 \\
\hline
\end{tabular}

The crystallites size of the grains in the films is estimated using the Sherrer's formula [14]:

$$
G=\frac{0.9 \lambda}{\beta \cos \theta}
$$

where $\lambda$ the wavelength of X-Ray used $(\lambda=1.5406 \AA), \beta$ the full width at half maximum peak of XRD pattern, and $\theta$ is the Bragg's angle. The values of grain sizes are found to be in the range $(1108-880 \mathrm{~nm})$.

The strain $(\sigma)$ of the films is determined with the use of the following formula [14]:

$$
\sigma=\left|\frac{c_{o}-c}{c_{o}}\right| \times 100 \%
$$

Where $\mathrm{c}_{\mathrm{o}}$ and $\mathrm{c}$ are lattice constant from ASTM and X-ray diffraction for ZnO respectively.

The calculated value of the grain size, and strain of un-irradiated and irradiated thin films are given in table (2 ), it is clear from the table, that the grain size for un-irradiated samples is greater than irradiated one, while the estimated strain values for irradiated samples is greater than un-irradiated one. This can be attributed to strong effect of $\gamma$-irradiation on the structure of the investigated samples.

Table (2): Values of grain size and strain of un-irradiated and irradiated $\mathrm{ZnO}$ films

\begin{tabular}{|c|c|c|c|}
\hline \multicolumn{2}{|c|}{ Un-irradiated } & \multicolumn{2}{c|}{ Irradiated } \\
\hline Grain size $\mathrm{nm}$ & Strain & Grain size $\mathrm{nm}$ & Strain \\
\hline 1108 & 0.48 & 880 & 0.33 \\
\hline
\end{tabular}

\section{ii. Optical Characterization}

The spectral behavior of transmittance, $\mathrm{T}$, and absorbance, $\mathrm{A}$, in the wavelength range $350-900 \mathrm{~nm}$ for un-irradiated and irradiated films illustrated in Fig. (3) and Fig. (4). A slight pronounced variation in transmittance, it is observed that the $\gamma$-irradiation shifts the transmission edge towards higher wavelengths indicating a decrease in the optical energy gap value. It is also observed that the intensity of transmittance peaks within the absorption region increases by irradiation. This is attributed to the presence of intraband transitions at localized states in the energy gap.

The optical band gap was calculated using following equations $[15,16]$ :

$$
\begin{aligned}
& \alpha h v=B(h v-E g)^{r} \\
& \alpha=-\ln (T) / t
\end{aligned}
$$

where ho is the photon energy, $\alpha$ is the absorption coefficient, Eg is the optical band gap, B is a constant $r=1 / 2$ for direct band gap material and $t$ is film thickness. Fig. (5) show a plot of $(\alpha h v)^{2}$ vs. photon energy (ho). The linear nature of the plot indicates the existence of direct transition. The band gap Eg, was determined by extrapolating the straight portion to the energy axis at $(\alpha \mathrm{hv})^{2}=0$, and are given in Table 3 . It was found to be $3.25 \mathrm{eV}$ for un-irradiated $\mathrm{ZnO}$ films and $3.2 \mathrm{eV}$ after irradiation. The decrease in band gap shows that the irradiated film causes a slightly 'red shift' in the optical spectra. This decrease in the optical band gap is 
basically due to the increase in the energy width of the band tails of localized states, similar observations have also been reported by other worker [17-19].

The absorption coefficient near the band edge shows an exponential dependence on photon energy [20]:

$\alpha=\alpha_{0} \exp \left[\frac{h v-E i}{E u}\right]$

Where $\mathrm{E}_{\mathrm{U}}$ is the Urbach energy which corresponds to the width of the band tail, $\mathrm{E}_{\mathrm{i}}$ and $\alpha_{\mathrm{o}}$ are constants. Thus, a plot of $\ln (\alpha)$ vs. ho should be linear and Urbach energy can be obtained from the slope. Fig. (6) shows the variation of $\ln (\alpha)$ vs. ho for the $\mathrm{ZnO}$ thin films. Urbach energy was calculated from the reciprocal gradient of the linear portion of these curves. The calculated values are given in Table 3. Urbach energy values of for unirradiated is less than that irradiated film. The $\mathrm{E}_{\mathrm{U}}$ values change inversely with optical band gap.

Optical constants define the interaction of light traveling through a material and are expressed as complex number and can be separated in to real and imaginary components. The most common representation are complex refractive index, $\mathrm{n}^{*}$, and complex dielectric constant $\varepsilon^{*}$. These two representations are related by [21]:

$$
\begin{aligned}
& \mathrm{n}^{*}=\mathrm{n}+\mathrm{ik} \\
& \varepsilon^{*}=\varepsilon_{\mathrm{r}}+\mathrm{i} \varepsilon_{\mathrm{i}}
\end{aligned}
$$

Where $\mathrm{n}, \mathrm{k}, \varepsilon_{\mathrm{r}}$ and $\varepsilon_{\mathrm{i}}$ are refractive index (real part), extinction coefficient (imaginary part), real part of dielectric constant and imaginary part of dielectric constant respectively. The extinction coefficient $\mathrm{k}$, describes the absorption of light as it travels through the absorption of light as it travels through the material can be calculated by the following equation[1,22]:

$$
k=\frac{\alpha \lambda}{4 \pi}
$$

Fig. (7) shows decrease of extinction coefficient with increasing wavelength for the films, and values of for unirradiated is less than that irradiated. The refraction index, real part and imaginary part of dielectric constants were calculated from the following equations [1,22]:

$$
n=\left[\left(\frac{1+R}{1-R}\right)^{2}-\left(k^{2}+1\right)\right]^{\frac{1}{2}}+\frac{1+R}{1-R}
$$

$\varepsilon_{\mathrm{r}}=\mathrm{n}^{2}-\mathrm{k}^{2}$

$\varepsilon_{\mathrm{i}}=2 \mathrm{nk}$

It can be observed from Fig. (8) to Fig. (10), the values of $n, \varepsilon_{\mathrm{r}}$ and $\varepsilon_{\mathrm{i}}$ dependence on the wavelength. The refractive index and real part of dielectric constant values of irradiated is less than that un-irradiated film, while imaginary part of dielectric constant values of un-irradiated is less than that irradiated film, this may be due to the change in crystallite size, stoichiometry and internal strain of films. The behavior of Er similar to the behavior of $\mathrm{n}$, because of smaller values of $\mathrm{k}^{2}$ in comparison with $\mathrm{n}^{2}$, but the behavior of Ei mainly depends on the variation of $\mathrm{k}$.

In the normal dispersion region the dispersion of refractive index has been analyzed using the single oscillator model which is analyzed according to the single - effective - oscillator model proposed by Wemple and Di Domenico [22-25].

$$
n^{2}-1=\frac{E_{d} E_{o}}{E_{o}^{2}-h v}
$$

Where $\mathrm{n}$ is the refractive index at a specific wavelength, $\mathrm{E}_{\mathrm{o}}$ is the average electronic energy gap for transition (average excitation energy) known as the oscillator energy, and $\mathrm{E}_{\mathrm{d}}$ is the dispersion energy (average strength of iterband optical transition) called the oscillator strength. By plotting $\left(\mathrm{n}^{2}-1\right)^{-1}$ vs. (hv $)^{2}$ as in Fig. (11) and fitting a straight line, the values of the parameters $E_{o}$ and $E_{d}$ were calculated from $\left(E_{o} / E_{d}\right)$ represents the intercept on the vertical axis and $\left(E_{o} E_{d}\right)^{-1}$ is the slope of the plot and listed in table 3. We found that average energy gap $E_{o}$ $=1.3 \mathrm{Eg}, \mathrm{E}_{0}=1.2 \mathrm{Eg}$ for un-irradiated and irradiated $\mathrm{ZnO}$ films respectively. This is good agreement with the result of other worker, where they found the relation between $\mathrm{E}_{\mathrm{o}}$ and $\mathrm{Eg}_{\text {is }} \mathrm{E}_{\mathrm{o}}=1.4 \mathrm{Eg}$ [25] and $\mathrm{E}_{\mathrm{o}}=1.2 \mathrm{Eg}[26]$. 
Table (3): Values of optical band gap, Urbach energy, oscillator energy and dispersion energy of un-irradiated and irradiated $\mathrm{ZnO}$ films

\begin{tabular}{|c|c|c|c|c|c|c|c|}
\hline \multicolumn{4}{|c|}{ Un-irradiated } & \multicolumn{5}{c|}{ Irradiated } \\
\hline $\mathrm{Eg} \mathrm{eV}$ & $\mathrm{Eu} \mathrm{eV}$ & $\mathrm{E}_{\mathrm{o}} \mathrm{eV}$ & $\mathrm{E}_{\mathrm{d}} \mathrm{eV}$ & $\mathrm{Eg} \mathrm{eV}$ & $\mathrm{Eu} \mathrm{eV}$ & $\mathrm{E}_{\mathrm{o}} \mathrm{eV}$ & $\mathrm{E}_{\mathrm{d}} \mathrm{eV}$ \\
\hline 3.25 & 0.61 & 4.23 & 8.05 & 3.20 & 0.73 & 4.16 & 5.14 \\
\hline
\end{tabular}

\section{Conclusion}

Thin films of $\mathrm{ZnO}$ have been prepared using DC-magnetron sputtering. Effect of gamma ray irradiation on the structural and optical properties has been investigated. The XRD data show the grain size being decreased after gamma ray irradiation. The optical absorption spectra of thin film $\mathrm{ZnO}$ are obtained in the wavelength range $350-900 \mathrm{~nm}$ before as well as after irradiation. The band gap is decreased and absorption coefficient $(\alpha)$ is increased after irradiation. Optical constants and the dispersion parameters of the films are affected by irradiation.

\section{References}

[1] Y. Jin, J. Wang, B. Sun, J.C. Blakesley and N. C. Greenham, "Nano Lett.", 8 (2008) 1649.

[2] Y. J. Lee, D.S. Ruby, D. W. Peters, B. B. Mckenzie and J. W. P. Hsu," Nano Lett.", 8 (2008) 1501.

[3] J. J. Schneider, R. C. Hoffmann, J. Engstler, O. Soffke, W. Jaegermann, A. Issanin and A. Klyszcz, "Advan. Mater.", 20 (2008) 3383 .

[4] A. M. Ibrahim and L. I. Soliman," Rad. Phys. \& Chem.", 53 (1998) 469

[5] E. Atanassova, A. Pasksleva, R. Konakova, D. Spassov and V. F. Mitin ,"Microelectronics J.", 32 (2001)553

[6] R. L. Clough ," Nucl. Instrum. Meth.", B185 (2001)8.

[7] E. Colby, G. Lum, T. Plettner and J. Spencer," IEEE Trans. Nucl. Sci.," NS-49 (2002) 2857.

[8] K. Arshak, A. Arshak, S. Zleetni and O. Korostynska," IEEE Trans. Nucl. Sci.", NS-51 (2004) 2250.

[9] K. Arshak, O. Korostynska, J. Molly and J. Harris," IEEE Sensors J.", 6 (2006) 656.

[10] K. Arshak and O. Korostynska," Mater. Sci. Eng.", B133( 2006)1.

[11] S. AMBILY, C. S. MENON, "Thin Sold Films", 347 (1999) 284.

[12] C. M. Marlene, F. M. Howard, E. H. Evons, G. Johan, P. Boris, Powder Diffraction Data, 1st Ed. Joint Comittee on Powder Diffraction Standards, USA,(1976) Diffraction Data Files no. 5-664.

[13] S. Ilican, Y. Caglar, M. Caglar, B. Demirci, "J. Optoelectronic and Advan. Mater.",10(10)(2008)2592.

[14] C. Gumus, O. M. Ozkender, H. Kavak, Y. Ufaktepe, "J. Optoelectronic and Advan. Mater.", 8(1)(2006) 299

[15] A. Ashour, "Turk. J. Phys.", 27 (2003) 551

[16] J. Huheey, Inorganic Chemistry, 3rd Ed. Harper and Row, New York (1983).

[17] S. L. Sharma and T. K. Maity, "Bull. Mater. Sci.", 34(1) February (2011) 61.

[18] T. J. Alwan, Turk. J .Phys. 36 (2012) 377.

[19] T. K. Maity and S. L. Sharma ,"India J. Pure Appl. Physc.",49 (2011)606

[20] J Tauc, Amorphous and Liquid Semiconductors, edited by J Tauc Plenum Press, New York, (1974)

[21] S. Ilican, M. caglar, Y. Caglar," J. Optoelectronic and Advan. Mater.", 9 (5) (2007) 1414.

[22] A. A. EL-Fadl, E. M. EL-Maghraby, G. A. Mohamad, "Cryst. Res. Technol.", 39 (2004) 143.

[23] A. A. Hendi, "Australian J. of Basic and Appl. Scie.", 5(10)(2011)8.

[24] S. H. Wemple, M. DiDomenico, "Phys. Rev. Lett.", 23 (1969) 1156

[25] S. H. Wemple, M. DiDomenico, "Phys. Rev.", B, 3 (1971) 1338.

[26] S. Ilican, Y. Caglar, M. Caglar, "Physica Macedonica" ,56 (2006) 43.

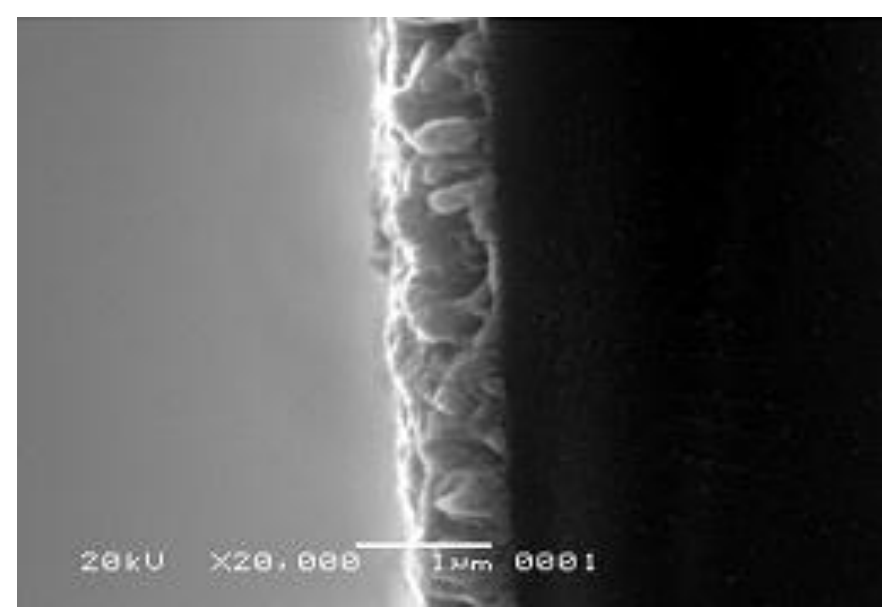

Fig. (1) SEM picture of cross sections as deposited $\mathrm{ZnO}$ film 


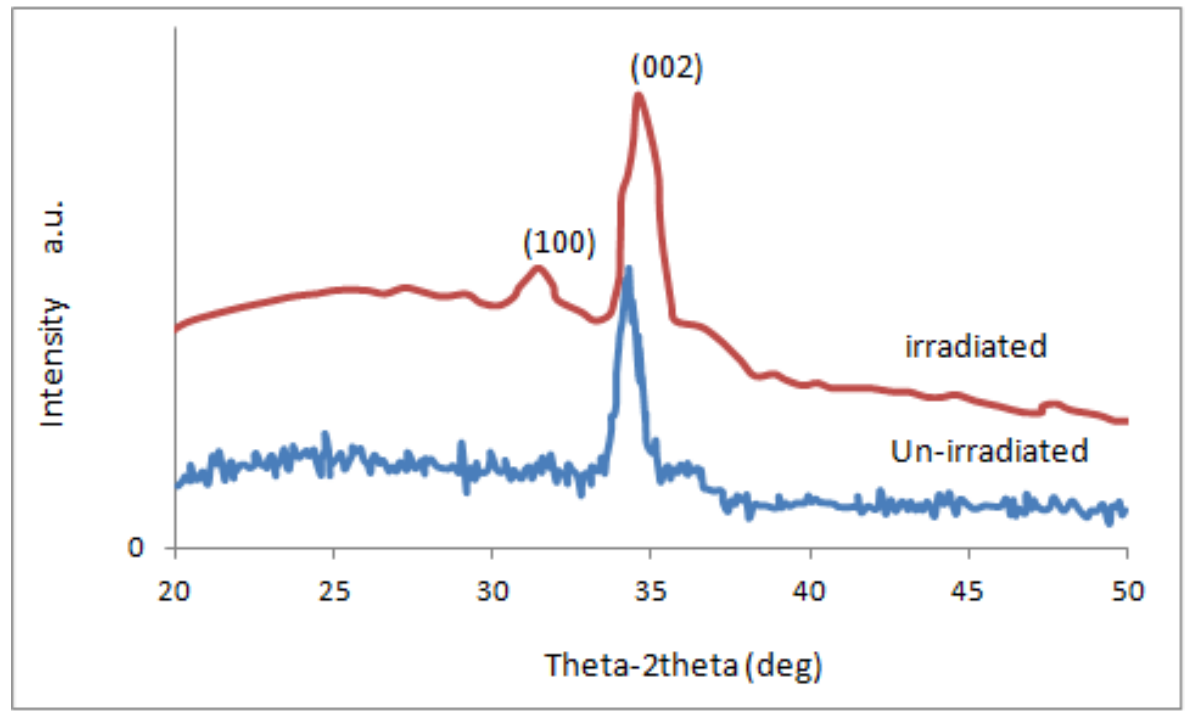

Fig (2) XRD patterns of un-irradiated and irradiated $\mathrm{ZnO}$ film
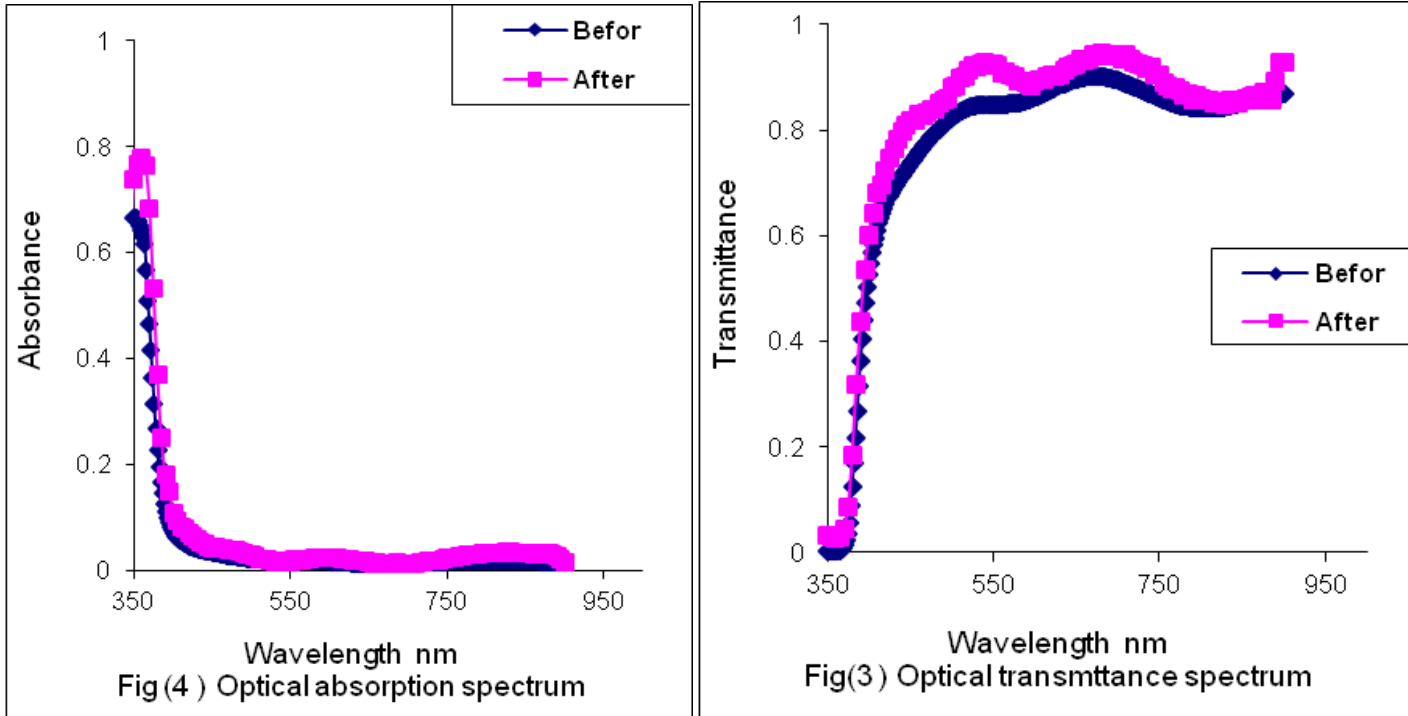

Fig(3) Optical transmttance spectrum

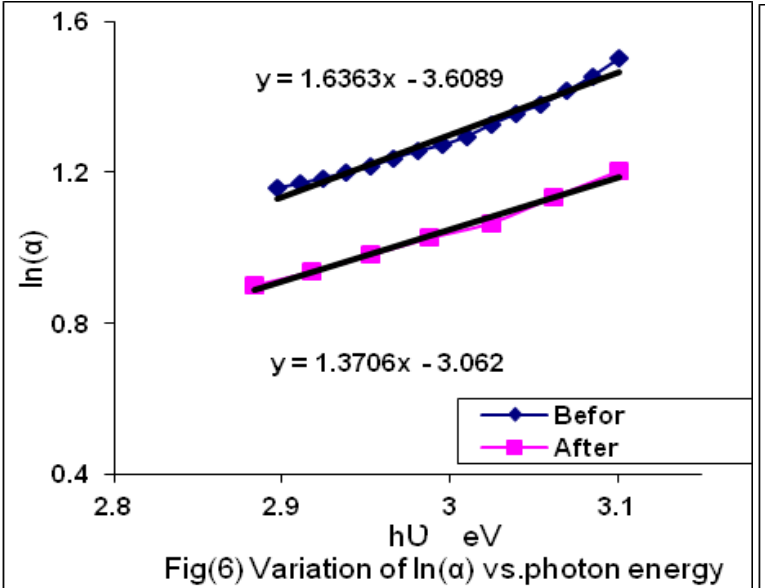

Fig(6) Variation of $\ln (\alpha)$ vs.photon energy

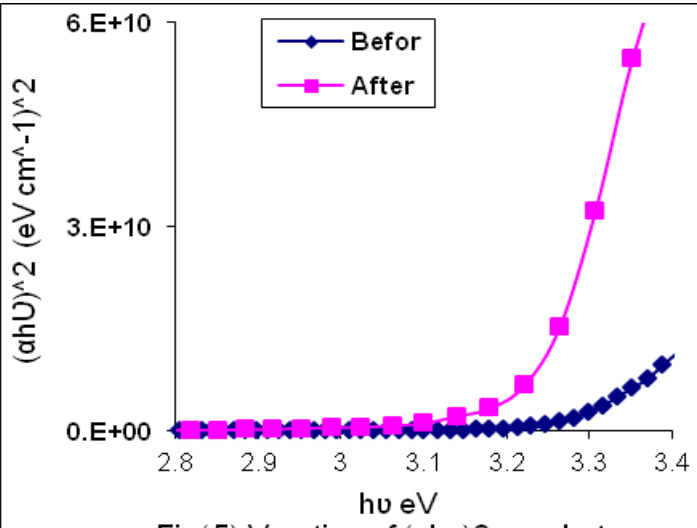

Fig( 5) Varation of (ahu)2 vs. photon energy 

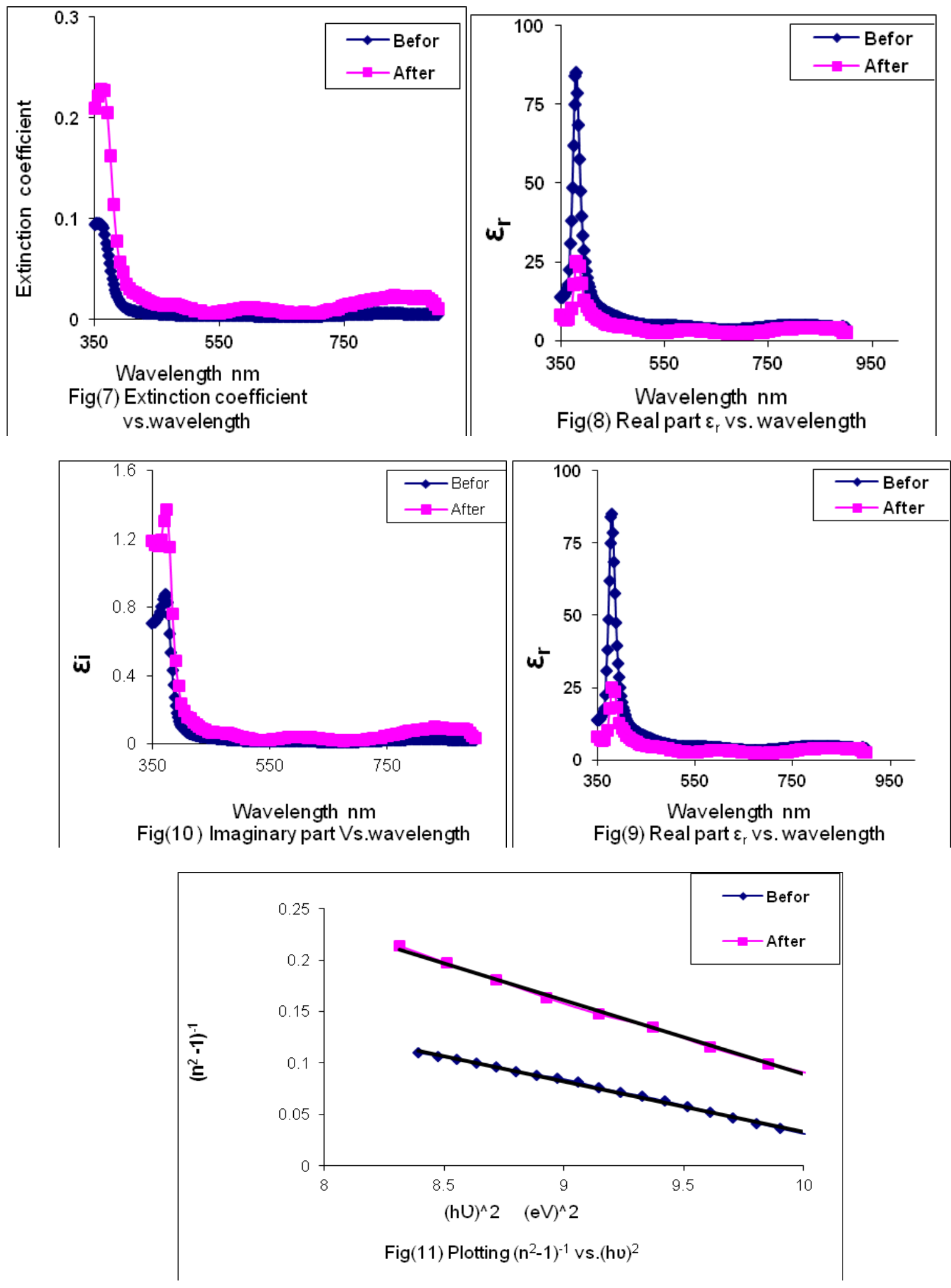